\title{
Design of Luminescent Single-Molecule Magnets
}

\author{
Mingzhe Nie, ${ }^{a, b}$ Chunru Wang, ${ }^{a}$ and Taishan Wang ${ }^{*, a}$ \\ ${ }^{a}$ Beijing National Laboratory for Molecular Sciences, Key Laboratory of Molecular Nanostructure and \\ Nanotechnology, Institute of Chemistry, Chinese Academy of Sciences, Beijing 100190, China \\ ${ }^{b}$ University of Chinese Academy of Sciences, Beijing 100049, China
}

Email: wangtais@iccas.ac.cn (T. W.)

\begin{abstract}
It's significant to design luminescent single-molecule magnets and promote their applications in high density data storage and magneto-luminescence devices. In this perspective, we highlight the advances in luminescent single-molecule magnets (SMMs), which have various types including metal complexes, metal-organic frameworks (MOFs), ionic liquids, metallofullerenes, and so on. Among them, metallofullerenes as an emergent luminescent SMMs show great prospects due to the varied metal clusters. Finally, we present perspectives and outlooks on the research directions in the future.
\end{abstract}

Keywords single-molecule magnet, photoluminescence, metal complex, metallofullerene

Luminescent single-molecule magnets (SMMs) represent a new class of dual-functional materials, featuring both magnetic properties and photoluminescence. This kind of material improves their potential applications greatly in high density data storage, quantum information processing, and magneto-luminescence devices. ${ }^{[1-3]}$ It thus has drawn extensive attention from worldwide researchers in the past decades.

Hitherto, several kinds of luminescent SMMs have been constructed, including metal complexes, ${ }^{[4-7]}$ metal-organic frameworks (MOFs), ${ }^{[8,9]}$ ionic liquids, ${ }^{[10]}$ metallofullerenes,${ }^{[11]}$ and so on. Among them, lanthanide ions have $4 f$ electrons with large magnetic anisotropy, which are widely used in SMMs. On the other hand, the abundant electronic levels of $4 f^{n}$ electronic configuration allow them to be employed as luminescent materials. Consequently, lanthanides are excellent candidates to exploit luminescent SMMs. Nevertheless, it's still crucial to explore new type of luminescent SMMs with better properties and to fabricate their devices.

Among these luminescent SMMs, a lanthanide-based metal complex is of importance, and plenty of them have been synthesized. It can be further categorized as monometallic, dimetallic and polymetallic luminescent SMMs. For example, a monodysprosium complex $\left[\mathrm{Dy}\left(\mathrm{Tp}^{\mathrm{py}}\right) \mathrm{F}(\right.$ dioxane $\left.)\right]\left(\mathrm{PF}_{6}\right)$ with a terminal fluoride ligand generates a large axial crystal-field splitting with $J=15 / 2$ ground state, and it exhibits obvious SMM behavior and slow relaxation of magnetization. In addition, emission spectra were observed both at 5 and $18 \mathrm{~K}$, which is ascribed to the ${ }^{4} \mathrm{~F}_{9 / 2} \rightarrow{ }^{6} \mathrm{H}_{15 / 2}\left(\approx 480 \mathrm{~nm}, 20830 \mathrm{~cm}^{-1}\right)$ and the ${ }^{4} \mathrm{~F}_{9 / 2} \rightarrow{ }^{6} \mathrm{H}_{13 / 2}\left(\approx 575 \mathrm{~nm}, 17390 \mathrm{~cm}^{-1}\right)$ transitions. ${ }^{[4]}$ A dimetallic complex $\left.\left[\mathrm{Yb}_{2} \text { (valdien }\right)_{2}\left(\mathrm{NO}_{3}\right)_{2}\right]$ behaves as a SMM with the highest energy barrier among $\mathrm{Yb}^{\prime \prime \prime}$-based SMMs, and its near-infrared emission at approximately $978 \mathrm{~nm}$ assigned to $\mathrm{Yb}^{\text {III }}{ }^{2} \mathrm{~F}_{5 / 2} \rightarrow{ }^{2} \mathrm{~F}_{7 / 2}$ was observed. Moreover, it can be employed as a luminescent thermometer over the $80-320 \mathrm{~K}$ temperature range. ${ }^{[5]}$ A linear trinuclear Dy $y^{\prime \prime \prime}$ complex $\left[\mathrm{Dy}_{3}(\mathrm{HSA})_{5}(\mathrm{SA})_{2}-\right.$ (phen $)_{3}$ ] exhibiting slow magnetic relaxation and emission peaks at 486 and $580 \mathrm{~nm}$ that is ascribed to the ${ }^{4} \mathrm{~F}_{9 / 2} \rightarrow{ }^{6} \mathrm{H}_{15 / 2}$ and ${ }^{4} \mathrm{~F}_{9 / 2} \rightarrow{ }^{6} \mathrm{H}_{13 / 2}$ transitions was designed. ${ }^{[6]}$

Lanthanide-based metal-organic frameworks (MOFs) were also utilized to design luminescent SMMs. A 3D framework $\left\{\mathrm{KDy}\left(\mathrm{C}_{2} \mathrm{O}_{4}\right)_{2}\left(\mathrm{H}_{2} \mathrm{O}\right)_{4}\right\}_{n}$ exhibits slow magnetic relaxation with high anisotropic barrier $(417 \pm 9 \mathrm{~K})$ and reversible ferromagnetic to antiferromagnetic phase transition upon dehydration and rehydration. Moreover, it also shows two characteristic peaks of $D^{\prime \prime \prime}$ at 485 and $576 \mathrm{~nm}$, corresponding to ${ }^{4} \mathrm{~F}_{9 / 2} \rightarrow{ }^{6} \mathrm{H}_{15 / 2}$ and ${ }^{4} \mathrm{~F}_{9 / 2} \rightarrow{ }^{6} \mathrm{H}_{13 / 2}$ transitions, respectively. ${ }^{[8]}$ Meanwhile, MOF $\left(\mathrm{H}_{6} \text { edte }\right)_{0.5}\left[\mathrm{Dy} \mathrm{y}^{\mathrm{III}}(\mathrm{ox})_{2}\left(\mathrm{H}_{2} \mathrm{O}\right)\right]$ shows frequency-dependent out-ofphase magnetic susceptibility and solid-state luminescence. ${ }^{[9]}$

lonic liquids are composed of distinct cations and anions, which can be used to design functional materials through appropriate ion combination. Three ionic liquids $\left[\mathrm{C}_{6} \mathrm{mim}\right]_{5-x}$ $\left[\mathrm{Dy}(\mathrm{SCN})_{8-x}\left(\mathrm{H}_{2} \mathrm{O}\right)_{x}\right] \quad(x=0-2)$ were synthesized, which are paramagnetic liquids at room temperature and show a strong response to conventional neodymium magnets. Furthermore, they all exhibit yellow emissions with long decay times, originating from Dy $\mathrm{III}^{\mathrm{II}}$.10]

Metallofullerenes are endofullerenes that encapsulate metallic species inside the hollow carbon cages, and they show abundant optical, electrical and magnetic properties. ${ }^{[12]}$ Owning to various endohedral cluster templates, metallofullerenes provide ideal option for designing multifunctional molecules. Recently, our group reported the first luminescent SMM of metallofullerene DyErScN@ $I_{h}-\mathrm{C}_{80}$, in which two functional lanthanide metal ions of Dy (SMM function) and $\mathrm{Er}^{\text {III }}$ (luminescent function) are integrated inside a fullerene cage using a trimetallic nitride template (Figure 1). DyErScN@ $I_{h}-\mathrm{C}_{80}$ presents

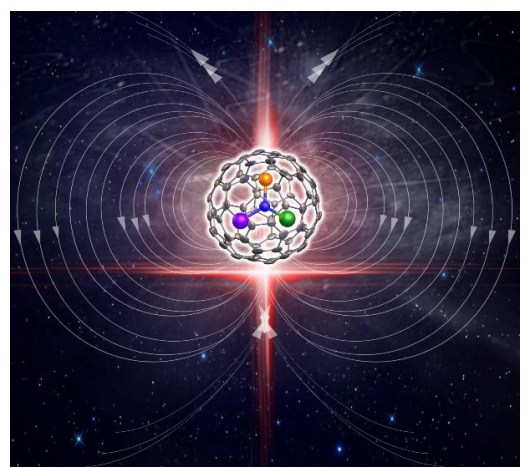

Figure 1 Luminescent single-molecule magnet of metallofullerene DyErScN@I $I_{h}-\mathrm{C}_{80}$. 
distinct SMM behavior with a blocking temperature up to $9 \mathrm{~K}$ resulting from the intramolecular magnetic interaction between $\mathrm{Dy}^{\prime \prime \prime}$ and $\mathrm{Er}^{\mathrm{III}}$ ions. Furthermore, DyErScN@/ $I_{h}-\mathrm{C}_{80}$ exhibits temperature-dependent near-infrared emission around $1.5 \mu \mathrm{m}$ with multiple splitting peaks from $\mathrm{Er}^{\text {III }}$. ${ }^{111]}$

Photoluminescence of luminescent SMMs under magnetic field has been investigated. Mononuclear [CsDy(8-mCND) $4_{4^{-}}$ $\left.\left(\mathrm{CH}_{3} \mathrm{OH}\right)\left(\mathrm{Me}_{2} \mathrm{CO}\right)\right]_{2} \cdot 2 \mathrm{Me}_{2} \mathrm{CO}$ behaves as single-molecule magnet with an effective energy barrier of around $95 \mathrm{~cm}^{-1}$, and temperature-dependent photoluminescence from Dy $y^{\text {III }}$ was also observed. Moreover, under pulsed magnetic field up to $36 \mathrm{~T}$, a shift of emission peaks was observed due to Zeeman effect. ${ }^{[13]}$ Likewise, this phenomenon of emission shift also occurs in a monometallic SMM $\left[\mathrm{Dy}\left(\mathrm{CyPh} \mathrm{PO}_{2} \mathrm{PO}\right)_{2}\left(\mathrm{H}_{2} \mathrm{O}\right)_{5}\right] \mathrm{Br}_{3} \cdot 2\left(\mathrm{CyPh}_{2} \mathrm{PO}\right)$. $\mathrm{EtOH} \cdot 3 \mathrm{H}_{2} \mathrm{O}$ with $\mathrm{D}_{5 h}$ local symmetry. Under a pulsed magnetic field from 0 to $37 \mathrm{~T}$, the emissions shift to lower wavenumbers and pairs of peaks split within the ${ }^{6} \mathrm{H}_{15 / 2}$ state of Dy ${ }^{\text {III }}$ due to the Zeeman splitting affects. ${ }^{[14]}$

In summary, scientists have explored some luminescent SMMs. It's still desirable to explore new type of luminescent SMMs. Notably, the metallofullerenes play an important role in designing newly emergent luminescent SMMs in the future due to their varied encapsulated metal clusters.

Furthermore, future works are expected to be done as follows: (1) Magneto-luminescence correlations are very useful for their applications in data storage. On the one hand, magnetic properties of luminescent SMMs can be modified by external light stimuli and thus the light can be used to write the information. On the other side, the photoluminescence of luminescent SMMs can be used to read the information recorded by magnets. Due to the single molecule form, the luminescent SMMs can promote the high-density data storage. (2) The luminescent SMMs have potential in magneto-luminescence or magneto-conductance devices, which need be studied in the future. For these devices, the magnetic field can be used to control the light emission or electron mobility, which is valuable for spintronics. (3) The magneto-luminescence correlation of luminescent SMMs can be utilized in the magneto-conception systems to sense the magnetic field of earth. The magnetic and luminance property of these materials is applicable to mimic the navigate systems in birds and other animals. (4) For luminescent SMMs, the luminescence signals can be employed as a sensor to detect the local magnetic field generated by SMMs. (5) special instrument should be developed to detect the single molecule property, including magnetism and luminescence.

\section{References}

[1] Stupakiewicz, A.; Szerenos, K.; Afanasiev, D.; Kirilyuk, A.; Kimel, A. V. Nature 2017, 542, 71.

[2] Ardavan, A.; Rival, O.; Morton, J. J. L.; Blundell, S. J.; Tyryshkin, A. M.; Timco, G. A.; Winpenny, R. E. P. Phys. Rev. Lett. 2007, 98, 057201.

[3] De Luca, M.; Polimeni, A.; Fonseka, H. A.; Meaney, A. J.; Christianen, P. C. M.; Maan, J. C.; Paiman, S.; Tan, H. H.; Mura, F.; Jagadish, C.; Capizzi, M. Nano Lett. 2014, 14, 4250.

[4] Norel, L.; Darago, L. E.; Le Guennic, B.; Chakarawet, K.; Gonzalez, M. I.; Olshansky, J. H.; Rigaut, S.; Long, J. R. Angew. Chem. Int. Ed. 2018, 57, 1933.

[5] Brunet, G.; Marin, R.; Monk, M.-J.; Resch-Genger, U.; Gálico, D. A.; Sigoli, F. A.; Suturina, E. A.; Hemmer, E.; Murugesu, M. Chem. Sci. 2019.

[6] Liu, C.-S.; Du, M.; Sañudo, E. C.; Echeverria, J.; Hu, M.; Zhang, Q.; Zhou, L.-M.; Fang, S.-M. Dalton Trans. 2011, 40, 9366.

[7] Long, J.; Guari, Y.; Ferreira, R. A. S.; Carlos, L. D.; Larionova, J. Coord. Chem. Rev. 2018, 363, 57.

[8] Mohapatra, S.; Rajeswaran, B.; Chakraborty, A.; Sundaresan, A.; Maji, T. K. Chem. Mater. 2013, 25, 1673.

[9] Akhtar, M. N.; Chen, Y.-C.; AlDamen, M. A.; Tong, M.-L. Dalton Trans. 2017, 46, 116.

[10] Mallick, B.; Balke, B.; Felser, C.; Mudring, A.-V. Angew. Chem. Int. Ed. 2008, 47, 7635.

[11] Nie, M.; Xiong, J.; Zhao, C.; Meng, H.; Zhang, K.; Han, Y.; Li, J.; Wang, B.; Feng, L.; Wang, C.; Wang, T. Nano Res. 2019, 12, 1727.

[12] Popov, A. A.; Yang, S.; Dunsch, L. Chem. Rev. 2013, 113, 5989.

[13] Bi, Y.; Chen, C.; Zhao, Y.-F.; Zhang, Y.-Q.; Jiang, S.-D.; Wang, B.-W.; Han, J.-B.; Sun, J.-L.; Bian, Z.-Q.; Wang, Z.-M.; Gao, S. Chem. Sci. 2016, 7, 5020.

[14] Chen, Y.-C.; Liu, J.-L.; Lan, Y.; Zhong, Z.-Q.; Mansikkamäki, A.; Ungur, L.; Li, Q.-W.; Jia, J.-H.; Chibotaru, L. F.; Han, J.-B.; Wernsdorfer, W.; Chen, X.-M.; Tong, M.-L. Chem. Eur. J. 2017, 23, 5708.

Received July 3, 2019 Accepted July 17, 2019 